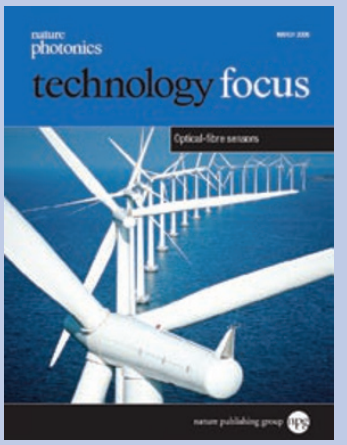

Cover image

Fibre sensors are being used to monitor the structural health of large composite structures such as turbine blades. Industry Perspective p153

EDITORS: NADYAANSCOMBE, OLIVER GRAYDON

PRODUCTION EDITOR: CHRIS GILLOCH COPY EDITOR: ANNA DEMMING ART EDITOR: TOM WILSON naturephoton@nature.com

\title{
Great potential
}

W e have been hearing about the great potential of fibre sensors for many, many years. There is no doubting that the technology can bring benefits to a wealth of applications, ranging from in situ sensors in the medical industry for monitoring important biological functions (page 150), through to vast distributed sensors in the oil industry (page 147). But despite their advantageous features, such as their immunity to electromagnetic interference, compact size and the ability to make distributed measurements, market penetration has been slower than expected in many areas.

Although deployments are now starting to rise and the market outlook over the next few years is optimistic (page 156), the question is why has it taken so long? The main reason is often nothing to do with the performance of the actual sensors themselves. For example, fibre Bragg grating technology has survived the rigours of scientific scrutiny and has proved itself in many field trials. The problem is largely a lack of awareness of the technology, a shortage of regulations to establish what measurements they should be used for and ultimately a question of cost (page 158).

The creation of standards and regulations is very important for encouraging or even demanding the use of sensors. For example, regulation demanding in situ lifetime monitoring of structures such as bridges would have an immediate impact on the fibre-sensor market and help avoid catastrophic accidents.

Industry standards and regulation would also help bring down cost - another barrier to growth. At present, sensor systems are often heavily customized and contain proprietary technology. The adoption of some common standards would help reduce costs. The bottom line is that increased regulation and standards, rather than new technology, are critical to the future success of fibre sensors.

\section{RESEARCH HIGHLIGHTS}

145 Monitoring pipelines, hydrogen leaks, traffic, and more

INDUSTRY PERSPECTIVE 147

Oil and gas applications:

Probing oil fields

Hilde Nakstad and

Jon Thomas Kringlebotn

150

Medical applications:

Saving lives

Éric Pinet

153

Structural-health monitoring:

A sensitive issue

Martin Jones

\section{BUSINESS NEWS}

156

Big contracts, more funding and market predictions

\section{PRODUCT HIGHLIGHTS}

157

Dynamic, robust and versatile sensors for diverse applications

\section{INTERVIEW}

158 Education and regulation Interview with Brian Culshaw 